\title{
Using CD-ROMs in teaching science: Findings from a small scale study
}

S. Rodrigues, G. Chittleborough, A. Gooding, T. Papadimitropoulos, V. K. Varughese, S. Kemp, J. Sadler, M. Gilmour, B. McKenna and S. Helme

University of Melbourne

\begin{abstract}
This paper reports on data collected through 52 surveys investigating teachers' use of CD-ROMs. The paper indicates that while teachers are familiar with the commonly voiced potential of CD-ROMs and recognise CD-ROM features of merit, the majority of teachers have yet to realise CD-ROM potential in the reality of their classroom. For many teachers issues of access to hardware or software continue to dictate their practices, where location rather than resource levels have established use. Consequently CD-ROMs have been promoted in terms of individual student assignments and other strategies involving whole class or group work have not been implemented.
\end{abstract}

\section{Introduction}

Information and communication technologies (ICT) such as dataloggers, the Internet, modelling, simulations, CD-ROMs and spreadsheets are commonly advocated for use in science classrooms (Brooks and Brooks, 1996; Rodrigues, 1996). For many teachers, the cost of datalogging kits and the difficulty in programming for modelling has limited the inclusion of these technologies in classroom practice. Similarly the cost, quality of access and the time to access relevant information has made Internet use within classroom time equally difficult. In contrast, CDROMs are thought to provide inexpensive access, quick and easy search mechanisms and a wealth of data in various forms (Brooks and Brooks, 1996). User-centred interactive environments are thought to have the potential to encourage students to become proactive learners (McCarthy 1989; Kozma, 1991; Harwood and McMahon, 1997) in a self-pacing and non-threatening environment. It is also possible that the interactive illustrations and links found in CD-ROMs could help students to contemplate the symbolic world of equations and formula, the macroscopic world of everyday substances and laboratory practices as 
well as the microscopic world of elementary particles (Brooks and Brooks, 1996). Simulations, often found in CD-ROMs have also been used in the development of science concepts dependent on graphical data (Trumper 1994; Lazarowitz \& Huppert, 1993). The particular value of simulations in a constructivist environment lies in their ability to provide a variety of contexts with a minimum of expenditure. An added bonus stems from ethics issues, where students have ethical concerns or loathe dissecting animals. Kinzie, Strauss and Foss (1993) and Strauss and Kinzie (1991) demonstrated that a simulation of a frog dissection was as potent as a 'real' dissection in terms of promoting learning about frog anatomy and dissection procedures.

Overall, it has been argued that the impact of CD-ROMs is four fold. They encourage robust concept development (Kearsley 1988; Gorsky and Finegold, 1992; Jones, 1994), influence different learning strategies (Marchionini 1988; Kirschner and Huisman, 1998), promote interconnectedness of knowledge (Costanzo 1988; Jones, 1994) and foster learner control (Trotter 1989; Harwood and McMahon, 1997). Therefore in theory there are several reasons why chemistry CD-ROMs could be effective tools when learning science. However, like practical work, motives for using CD-ROMs vary.

Some of the many motives for using practical work in science classrooms relates to the perceived ability of practical work to illustrate or confirm scientific theory and its ability to help distil insight into scientific phenomena (Hodson, 1988). Others believe that practical work provides a more meaningful learning experience in comparison with rote learning (Hodson, 1988). Many of these beliefs and perceptions are being mirrored in the cited potential of CD-ROMs. There is a belief that the interactiveness and animations found in CD-ROMs will provide meaningful learning environments that could help distil insight into particular phenomena while providing subservience to the theory being touted in the classroom. For example, numerous visualisation techniques are available that allow, for example, students to play back and analyse the motion of objects (see Pearce, Livett and Rodrigues, 1998; Chaudhury and Zollman, 1994). Maor and Taylor (1995) suggested that scientific databases could provide students with scope to engage in scientific inquiry and become involved in negotiating meaning and producing creative research questions. 
While there is a large body of research literature reporting on practical work in science classrooms in terms of teachers' pedagogical content knowledge, there is little available with respect to the use of information communication technologies. The potential of CD-ROMs is very dependent upon teachers' pedagogical content knowledge, rather than simply the format and content of a CD-ROM.

Teachers' prior practices and routines influence changes teachers make in their classrooms to accommodate technology (Miller and Olson, 1994). Evidence from Apple Computers' effort to integrate education technology into classroom practice indicates that full advantage of the available technology did not eventuate until the project was almost three years old, allowing time for teacher change (Dwyer, 1996). According to Miller and Olson (1994) teachers tend to modify the technology to fit their teaching styles rather than modify their teaching style. Cuban (1986) suggested that the introduction of technology to classrooms often adopt a cyclical pattern:

1. initially reformers introduce the innovation,

2. academic studies demonstrate the effectiveness of the innovation in comparison with conventional strategies,

3. complaints about incompatibility and or imperfection are voiced,

4. infrequent use of the technology occurs

5. administrators are criticised for minimising access and teachers criticised for intransigence.

In this paper we document some teachers reported use of CD-ROMs in science education with a view to determining what, if any, changes in pedagogical content knowledge (Shulman, 1987) are signalled when a formal effort to integrate ICT use does not exist. Yet, even though there is fairly widespread availability with respect to CD-ROM use in schools, and there is much cited about the value of these technologies in learning science, there is limited reporting with respect to teachers' perception of and use of these technologies as classroom tools. Though quite clearly, as McLauglin and Talbert (1990) have already suggested, effective teaching would depend on how teachers think and feel about what they do.

In this paper we report on how teachers think and feel about the use of CD-ROMs in teaching chemistry. The paper also reports on teachers' reasons for using CD-ROMs and the manner in which they currently deploy CD-ROMs in their classrooms. 


\section{Methodology}

The data presented in this paper originates from a sample drawn from various groups of science teacher who voluntarily completed surveys. The sample includes teachers who were mentors to students during final student-teaching rounds, teachers who attended a science teachers' conference and teachers who attended an ICT professional development day. Of the fifty mentor teachers contacted, 18 completed surveys, the rest indicated they did not use CD-ROMs. Seventy teachers attended the ICT day, 25 teachers completed surveys and the rest stated that they did not use CD-ROMs. Nine teachers at a science teachers' conferences voluntarily completed surveys. Hence in total 52 teachers voluntarily completed surveys. The findings from the surveys were coded to reflect the teacher sample. Hence teachers attending the ICT day were given a code ICT and a number to identify the teacher, the remainder of the sample, (science teacher mentors and science teachers at the conference), were given a code RTS (remaining teacher sample) and a number to identify the teacher. The surveys sought to document science teacher pedagogical content knowledge by asking the teachers to reflect on their own lessons and articulate the 'what?' 'how?' 'where?' and 'why?' of their teaching involved the use of CD-ROMs. The surveys were based on surveys used by Lehman and Brickner (1996) in their investigation into 36 teachers' use and perception of interactive videodiscs in the science classroom, and the surveys used by Germann and Barrow (1996) in their investigation into 635 teachers use of computer technologies in science classrooms.

Once the surveys were completed and coded to identify the source, a team of researchers comprised of classroom teachers, student teachers, academics and educational researchers collated the data. The teams worked in two groups of four to identify themes and to classify the teachers' responses. Each group then presented their criteria, analysis and themes to the other group. Discussion ensued until consensus was reached with respect to the criteria and classifications.

\section{Findings}

The fifty-two surveys were completed to various degrees. The majority of those teachers who completed the survey had significant teaching experience. Over two thirds had been teaching for more than seven years. 


\begin{tabular}{|c|c|c|c|}
\hline Group & government & non-government & no response \\
\hline ICT & 16 & 7 & 2 \\
\hline RTS & 13 & 12 & 2 \\
\hline Total & 29 & 19 & 4 \\
\hline
\end{tabular}

Table 1. Teachers and their school

In general the ICT sample group perceived themselves to have a high levels of ICT skills, whereas the remaining science teacher sample either did not provide an indication of their skill level or considered themselves to be average. As we can see from table 2, only eight respondents said there was a school or department policy for ICT integration in science.

\begin{tabular}{|c|c|c|c|c|}
\hline Group & yes & no & no response & other \\
\hline ICT & 4 & 18 & 3 & 0 \\
\hline RTS & 4 & 10 & 12 & 1 \\
\hline Total & 8 & 28 & 15 & 1 \\
\hline
\end{tabular}

Table 2. School ICT policy

Interestingly, the majority of the ICT group did not have a school strategy or policy for ICT integration, but they were nevertheless seeking professional development by attending an ICT day.

Findings from this small survey are documented under three broad areas:

- Location and access of CD-ROMs

- Features and format of CD-ROMs

- Organisation, use and management of CD-ROMs

\section{Location and access}

This section reports on issues of access and location with respect to CDROMs for science. One of the major issues voiced with respect to CDROM use in Science was the lack of accessibility for both students and teachers. The issue of access did not simply imply a lack of resources in schools but rather, due to the location of available resources, a lack of access:

I have the problem that many science staff have in getting access to computer (CD-ROM) use. Although we have fairly good computer numbers it is still difficult to get classes booked in. (RTS 5)

No computers in labs. One room of computers for school: access problem.

(RTS 25)

No access or computer room booked out. (RTS24) 
The majority of teachers indicated that facilities were present but not necessarily available. This was a commonly voiced concern regarding access to rooms with computers The teachers believed there were benefits stemming from the use of CD-ROMs, but due to limited resources and time, many felt that using CD-ROMs during lessons was not a viable option.

\footnotetext{
I think it is a very good idea, however we are limited by fund (s), time and resources (computers in classroom) and no network system. (RTS 4)

Vastly superior to Internet but still has two main concerns: availability

(under resourced government schools) (RTS 6)
}

The lack of access to computers and thus CD-ROMs was a reflection of the location of the hardware rather than an indication of resource levels in schools. Twenty-four teachers indicated that CD-ROMs for chemistry were located in the school library. Just under a third of the sample did not have hardware available to operate CD-ROMs for chemistry classes. Only five teachers indicated that the CD-ROMs were located in their chemistry laboratory. Software storage of CD-ROMs also affected access.

1 CD-ROM in library, 1 CD ROM in staffroom (ICT 26)

CD-ROMs are kept in computer labs for IT students in one lab (ICT 20)

CD-ROMs are kept: in Science department prep area. (ICT 16)

Consequently, the main use of CD-ROMs for Chemistry involved student research tasks. Teachers provided CD-ROMs as an alternative to textbooks or videos, mainly for student assignments and CD-ROMs that were not readily available were rarely used. Therefore the location of hardware and software is having a marked impact on the use of CDROMs in science classrooms.

\section{Features and formats of CD-ROMs}

The following is a ranked list of criteria that teachers used to purchase CD-ROMs. The most commonly cited reason is listed first. Teachers purchased CD-ROMs because of their:

- relevance to the curriculum, topic, and level

- ease of use

- interactiveness

- price

- multimedia aspect

- factually correct information

- accompanying support material

- technical compatibility

- student interest, Australian product, awards or recommendations 
The manner in which teachers made use of these features of the CD-ROM would provide a clue with respect to changes in pedagogy to suit the technology or whether technology was being used to fit existing teaching styles. Teachers commented on numerous aspects of CD-ROMs (Table 3).

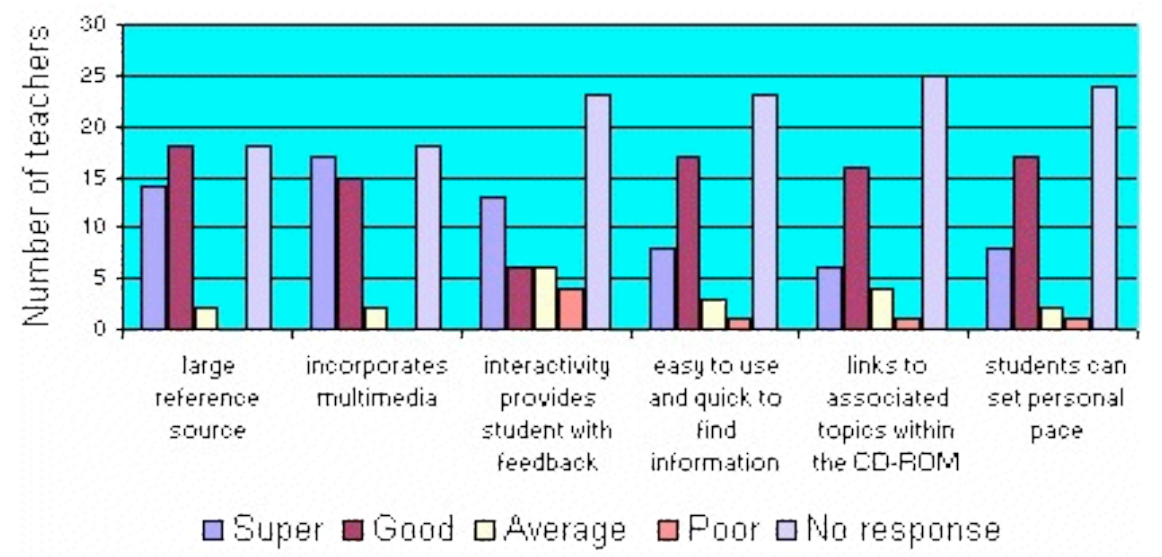

Table 3: Teachers' view regarding features of CD-ROMs

Most teachers identified CD-ROM benefits either in terms of their significance to particular topics or their ability to provide support for student learning. Consequently more than half signalled that they promoted the use of CD-ROMs in student assignments. Many teachers suggested that CD-ROMs were valuable resource materials but the reason for this perceived value varied:

\section{Quality of information}

Download pictures etc for assignments (RTS 8)

Access to information for assignments (ICT 13)

Broadens student research base (RTS 1)

To help students learn challenging ideas (RTS 20)

Make it more interesting not so teacher orientated (ICT 24)

Strengths not available through other learning media

Makes modelling easy (RTS 5)

Enhances visual displays (ICT 9)

For the diagrams to show things you cannot usually see (RTS17)

2. Interactiveness and option for self pace

Self paced learning (ICT 8)

Learner interactive (RTS 7)

More engaging for all students (RTS 7)

Interactive, provide instant feedback (ICT 11) 
3. CD-ROMs complemented their style of teaching:

To complement existing materials, provide a different point of view (RTS11)

To reinforce topics covered in class or introduced previously (ICT 19)

To give repetitive practice at completing exercises (ICT 19)

\section{Organisation, use and management of CD-ROMs}

Teachers were asked to indicate the role of CD-ROMs in their teaching and learning environments. To what extent and how was teaching style changing? These questions were investigated in terms of the manner in which CD-ROMs were used with respect to task set and with respect to management issues. Seventeen teachers indicated that they used CDROMs in lesson planning, but twenty-three teachers did not use CDROMs in planning for lessons. Twenty-five teachers indicated that they did not use worksheets with CD-ROMs. Twenty teachers stated that CDROMs did not save teachers time, and twenty-three teachers were undecided.

The majority of teachers (31) did not use CD-ROMs in tests or use CDROMs as rewards for students who completed work quickly. The majority of teachers (29) did not use CD-ROMs in practical lessons. Management questions investigated how teachers organised CD-ROM use. Teachers provided numerous suggestions with regard to organising students working with CD-ROMs. Although the majority of teachers indicated that best use of CD-ROMs would be accomplished by individuals when conducting research for projects/assignments or when revising for tests.

Working individually students can work at their own pace.(ICT 26)

Library resource and individual work and projects, assignments. (RTS 21)

Working individually students can work at their own pace. (ICT 26)

But some teachers felt that opportunities to work in groups provided a non threatening environment that encouraged students to help each other during the learning process. While other teachers suggested that working in groups may lead to one individual taking ownership and overall control of the task. Some teachers stated that CD-ROM use depended on the nature of the task and the access to resources.

Revision work individually. Assignment work, introduction to concepts

in small groups. (RTS 6)

Small groups when doing parts of a joint project. Individually when

revising for tests. (RTS 31)

Research as individual. Problem solving in groups. (RTS 1) 
A review of teachers responses with respect to access to computers would indicate that teachers choice of group or individual work was a consequence of the availability of computers.

Whole class teaching involving CD-ROMs was not widely practised. Overall, teachers considered CD-ROM use to be a failure when inadequate facilities were available, when the quality of the CD-ROM was poor, or when there appeared to be no real advantage over hard text materials.

\section{Discussion}

Chemistry CD-ROMs have a lot of potential, due mainly to the volume of inexpensive accessible data, and their ability to illustrate microscopic, macroscopic and symbolic level chemistry. However creating opportunities to use these levels effectively, depend on teachers' pedagogical content knowledge. This pedagogical content knowledge with particular reference to CD-ROM use is still evolving.

CD-ROM use in the classroom is still pedestrian. Primary use of CDROM tends to be as a resource for project work. This is most likely a consequence of lack of available resources. Having access to hardware to read CD-ROMs or having quality CD-ROMs does not result in appropriate or effective use. Teachers were not familiar with a variety of teaching strategies (see for example Rodrigues and Corrigan 1998) that could be used with CD-ROMs in order to increase effectiveness of limited resources.

According to Miller and Olson, (1994) teachers tend to modify the technology to fit their teaching styles rather than modify their teaching style. The survey data would indicate that teachers used the technology in a limited way rather than modify their teaching style to maximise use and effectiveness of features they identified the CD-ROMs to have. The number of teachers attending ICT sessions at conferences and the proliferation of ICT courses and materials indicates a market for teacher professional development in terms of ICT experience and ICT pedagogy practice.

Clearly teachers are considering their options with respect to using ICT in science classrooms. However, given the survey data, professional development courses need to consider meeting teachers' needs in terms of: 
- Knowing how to organise use of ICT in classrooms given a range of resource levels

- Familiarisation and understanding of the role of various ICT features

- ICT features that best lend themselves to contemplating the symbolic, the macroscopic and the microscopic worlds commonly encountered in science.

However, without a sound conceptual framework, the use of CD-ROMs in science classrooms may experience the same problems that face practical work. Allowing students to follow poorly designed simulations or animations is dangerous. Furthermore, because CD-ROMs offer students non linear access to information, potentially the learner becomes more responsible for their learning process (Newmark, 1989) but learner control is not necessarily automatic and some learners may not simply require access, they may require learner guidance. Familiarising teachers with a range of good quality CD-ROMs and best practice teaching strategies should help address some of these needs. It is only through a review of teachers' pedagogical content knowledge that teachers are likely to review their teaching style to adapt to the inclusion of ICT in a meaningful and enhanced manner. For teacher educators and researchers simply signalling the potential of ICT is not enough, signalling how to realise this potential in the reality of a classroom is clearly warranted. Instead of touting how the use of ICT enhances student learning, we should now be illustrating some of the most effective ways for teachers to use the ICT to enhance learning.

This small scale research exercise reported in this paper supports the view expressed by Dwyer, Ringstaff, Haymore-Sandholtz \& Apple computer Inc (1990a, 1990b), and by Harwood and McMahon (1997), that simply having access to computers and multimedia in schools is not enough in terms of affecting student learning. Advocating the use of ICT in classroom practice, providing resources and making available these resources does not result in effective use of the ICT, but accompanying professional development is thought to enhance the likelihood of effective use. Without teacher facilitation, the merits of ICT use in classrooms will remain illusive. Without teacher professional development inordinate amounts of money and time will be wasted on purchasing equipment that will be used in a limited manner. 


\section{References}

Brooks, H. B. and Brooks, D. W. (1996). The emerging role of CD-ROMs in teaching Chemistry. Journal of Science Education and Teaching, 5, 3, 203-215.

Chaudhury, S. R. and Zollman, D. A. (1994). Image processing enhances the value of digital video in physics instruction. Computers in Physics Education, 8, 518-523.

Costanzo, W. V. (1988). Media, metaphors and models. English Journal, 77(Nov), 2832.

Cuban, L. (1986). Teachers and machines: The classroom use of technology since 1920. New York: Teachers College Press.

Dwyer, D. C., Ringstaff, C., Haymore-Sandholtz, J. \& Apple Computer Inc, (1990b). Teacher Beliefs and practices, part II: Patterns of change. The evolution of teachers' instructional beliefs and practices in high- access-to technology classrooms. First - fourth Year findings. Apple Classrooms of Tomorrow Research Report Number 9.

Dwyer, D. C., Ringstaff, C., Haymore-Sandholtz, J. \& Apple Computer Inc, (1990a). Teacher Beliefs and practices, part I: Patterns of change. The evolution of teachers' instructional beliefs and practices in high- access-to technology classrooms. First - fourth Year findings. Apple Classrooms of Tomorrow Research Report Number 8.

Dwyer, D. C. (1996). The imperative to change our schools. In C. Fischer and K. Yocam (Eds), Education and technology: Reflections on computing in classrooms (pp 15-34). San Francisco: Jossey Bass.

Germann, P. J. and Barrow, L. H. (1996). The use of computer technologies in Missouri Secondary Science Classrooms. Journal of Computers in Mathematics and Science Teaching, 15(3), 217-236.

Gorsky, P. and Finegold, M. (1992). Using computer simulations to restructure students' conception of force. Journal of Computers in Mathematics and Science Teaching, 11, 163-178.

Harwood, W. S. and McMahon, M. M. (1997). Effects of integrated video media on student achievement and attitudes in High School Chemistry. Journal of Research in Science Teaching, $34,6,17-631$.

Hodson, D. (1988). Experiments in science and science teaching. Educational Philosophy and Theory, 20, 53-66.

Jones, T. (1994). Video and multimedia for math and science instruction. Journal of Computers in Mathematics and Science Teaching, 13, 128-145.

Kearsley, G. (1988). Authoring considerations for hypertext. Educational Technology, 28(11), 21-24.

Kinzie, M. B., Strauss, R. \& Foss, J. (1993). The effects of an interactive dissection simulation on the performance and attitudes of high school biology students. Journal of Research in Science Teaching, 30(8), 989-1000.

Kirschner, P. and Huisman, W. (1998). Dry laboratories in science education; computer-based practical work. International Journal of Science Education, 20(6), 665-682. 
Kozma, R.B. (1991). Learning with media. Review of Educational Research, 61(2), 179211.

Lazarowitz, R. \& Huppert, J. (1993). Science process skills of 10th grade biology students in a computer assisted learning setting. Journal of Research on Computing in Education, 25(1), 366-381.

Lehman, J.D and Brickner, D. (1996). Teachers' uses and perceptions of Interactive Videodiscs in the Science classroom. Journal of Computers in Mathematics and Science Teaching, 15(1/2), 85-102.

Maor, D. and Taylor, P.T. (1995). Teacher Epistemology and scientific inquiry in computerised classroom environments. Journal of Research in Science Teaching, 32(8), 839-854.

Marchionini, G. ( 1988). Hypermedia and learning: Freedom and chaos. Educational Technology, 28,11, 8-12.

McCarthy, R ( 1989). Multimedia: What the excitement's all about. Electronic Learning, 8 (Jun), 26-31.

McLaughlin, M. W. and Talbert, J. E. (1990). The context in question. The secondary school workplace. In M.W. McLaughlin, J.E. Talbert and N Bascia (Eds), The context of teaching in secondary schools: Teachers realities. New York: Teachers College Columbia University.

Miller. L. and Olson, J. (1994). Putting the computer in its place: A study of teaching with technology. Journal of Curriculum Studies, 26(2), 121-141.

Pearce, J., Livett, M. and Rodrigues, S. (1998). Development and use of an on-line video analysis tool for physics learning. Apple University Consortium Academic Conference Proceedings. Melbourne University, Melbourne, 27-30 September 1998. CD-ROM A8G12QK4S.

Rodrigues, S. (1996). Review of computer based technologies on students' learning school science. p62 -101. In P.C.Clarkson and R. Toomey (Eds.), Computing across the Secondary Curriculum: A review of research. Melbourne: Deakin University Printery, National Professional Development Project, Computers Across the Secondary Curriculum Reference Group.

Rodrigues, S. and Corrigan, D. (1998). Including IT: Managing information technology in the science classroom. Christchurch: User Friendly Resources.

Shulman, LS (1987). Knowledge and teaching: Foundations of the new reform. Harvard Educational Review, 57, 1-22.

Strauss, R. \& Kinzie, M. B. (1991). Hi tech alternatives to dissection. American Biology Teacher, 53, 154 -158.

Trotter, A. (1989.) Schools gear up for hypermedia: A quantum leap in electronic learning. American School Board Journal, 176(Mar), 35-37.

Trumper, R . (1994). Computer assisted teaching of physics. Journal of Computers in Mathematics and Science Teaching, 13(2), 183-195.

S. Rodrigues, G. Chittleborough, A. Gooding, T. Papadimitropoulos, V. K. Varughese, S. Kemp, J. Sadler, M. Gilmour, B. McKenna and S. Helme. University of Melbourne, Parkville Vic 3052, Australia 